Musées, Patrimoine et Culture scientifiques et techniques

$153 \mid 2014$

mai-juin 2014

\title{
Le récolement décennal : premiers éléments de bilan
}

Philippe Saunier

\section{(Q) OpenEdition Journals}

Édition électronique

URL : http://journals.openedition.org/ocim/1364

DOI : $10.4000 /$ ocim. 1364

ISSN : 2108-646X

\section{Éditeur}

OCIM

\section{Édition imprimée}

Date de publication : 25 juin 2014

ISSN : 0994-1908

\section{Référence électronique}

Philippe Saunier, «Le récolement décennal : premiers éléments de bilan », La Lettre de I'OCIM [En ligne], 153 | 2014, mis en ligne le 26 juin 2016, consulté le 21 avril 2019. URL : http:// journals.openedition.org/ocim/1364; DOI : 10.4000/ocim.1364 


\title{
Le récolement décennal : premiers éléments de bilan
}

\author{
Philippe Saunier \\ Conservateur du patrimoine, chef du bureau de l'inventaire des collections \\ et de la circulation des biens culturels, ministère de la Culture et de la Communication
}

Sans doute le récolement des collections, parce qu'il a été rendu obligatoire par la loi sur les musées de France, est-il perçu par certains comme une contrainte; il s'agit en réalité d'une mission fondamentale, à double titre : non seulement il doit garantir la consistance des collections, mais il permet également d'appréhender dans le détail la nature des œuvres, leur localisation, leur état, toutes choses qui doivent fonder la politique de l'établissement en termes de présentation, d'acquisitions, de restaurations.

Ce premier récolement décennal s’achèvera le 12 juin 2014. Sans attendre l'exploitation des données relatives à l'activité de 2013 et du premier semestre de l'année en cours, le Service des musées de France a établi un bilan provisoire, d'où il ressort que le volume des collections à récoler dans les musées de France s'élève à 47 millions de biens environ (non compris les œuvres appartenant aux musées nationaux relevant d'autres ministères que celui de la Culture). À la fin de l'année 2012, le nombre de biens récolés était de 9,6 millions, soit un taux légèrement supérieur à $20 \%$. Ce volume modeste au regard de l'objectif d'un achèvement dans quelques semaines est à relativiser : dans la plupart des cas, le chantier du récolement n'est vraiment entré dans sa phase opérationnelle qu'autour de 2008 ; il s'agit par ailleurs d'une opération compliquée par l'absence ou le caractère incomplet de très nombreux inventaires; enfin, le taux de récolement est fortement impacté par une poignée de musées aux collections numériquement colossales (une cinquantaine de musées ont, à eux seuls, plus de trois quarts du volume total des biens à récoler).
Même si les 100\% ne seront pas atteints en juin 2014, le Service des musées de France a pu vérifier que le rythme décennal était cohérent. En effet, le rendement moyen, à l'échelle de l'ensemble des musées de France, est de 2000 objets récolés par musée et par an, soit 20000 objets en dix ans ; à ce rythme, deux tiers des musées de France sont donc en capacité d'atteindre l'objectif. Reste le cas particulier des muséums et des collections archéologiques, dont le volume hors norme appelle une réponse adaptée. Pour ces derniers, l'ambition du Service des musées de France est de préparer un texte sur la méthodologie du récolement des ensembles complexes.

Par ailleurs, le Service des musées de France a mené une enquête pour déterminer, en fonction des types de musées, le rendement d'un équivalent temps plein (ETP) consacré exclusivement au récolement. Sur cette base, il proposera qu'une contractualisation soit menée au niveau des DRAC pour fixer, avec chaque musée retardataire, un calendrier ambitieux et néanmoins réaliste d'achèvement. Enfin, pour tous ceux qui auront terminé, il conviendra de mettre en œuvre les opérations de post-récolement (marquage des œuvres, inscriptions rétrospectives à l'inventaire, radiations...). Un soin particulier devra être apporté à l'établissement de la liste des œuvres non vues de sorte que le Service des musées de France puisse constituer le catalogue national des biens manquants, outil indispensable à la vérification du pedigree des œuvres se retrouvant sur le marché. 